\title{
Understanding African American Women's Resilience in the Face of Allostatic Load
}

\author{
Karen Patricia Williams
}

Published online: 23 January 2019

(C) The New York Academy of Medicine 2019

On the tombstone of Fannie Lou Hamer, a leader in the Civil Rights Movement who died of complications from hypertension and breast cancer, it says "I am sick and tired of being sick and tired." Although Mrs. Hamer's famous quote was in the context of living under the tyranny of the South's Jim Crow, her sentiments are salient for African American women today. Oddly enough, the twentieth century issues that Fannie Lou Hamer and other civil rights leaders fought and shed their blood for are ever present in the twenty-first century. Issues such as voting rights, job discrimination, and housing continue to impact the quality of life among African American women and in turn affect their health. Today, African American women find themselves in unwanted leadership positions, where they have almost double the rates of obesity, diabetes, and hypertension compared with White women, resulting in higher mortality rates for these women. The persistence of disparity requires reexamining this complex phenomenon. As researchers and scholars, we will need to reframe our questions. We will need to move beyond the pedestrian questions that emanate from a single lens. We will need to challenge ourselves to using multiple lenses simultaneously, with the understanding that African American women are more than negative health statistics. Moreover, we will need to keep in mind that African

K. P. Williams $(\bowtie)$

Martha S. Pitzer Center for Women, Children and Youth, College of Nursing, The Ohio State University, 362 Newton Hall, 1585

Neil Avenue, Columbus, OH 43210, USA

e-mail: williams.5963@osu.edu
American women are not monolithic but diverse as pointed out by poet Mona Lake Jones, they are “... Jugglers of profession, managers of lives; Mothers of children, lovers and wives; Good hearted, reaching out to others; Giving back to the community and supporting their brothers; All these sisters struggled through the path they had come...."

In the summer of 2018, the Martha S. Pitzer Center for Women, Children and Youth at The Ohio State University convened women's health stakeholders to discuss changing the research paradigm as it relates to African American women. The summit "Flip the Script: Understanding African American Women's Resilience in the Face of Allostatic Load" comprised of African American women across the life span; other stakeholders were from academe, state government, local health departments, as well as experts from across the country. The summit used the National Institute of Minority Health and Health Disparities research multilevel framework that includes life course, health outcomes, and levels of influence such as the biological, behavioral, built environment, socio-cultural environment, and healthcare systems. Like the summit, this special supplement reflects a multilevel framework that includes some of the papers presented at the summit as well as invited submissions.

Rather than having papers that only examined resilience, which is a multidimensional characteristic that varies with context, time, age, gender, and cultural origin, as well as within an individual subjected to different life circumstances [1], we thought it necessary to look at resilience in the context of allostatic load, the body's 
maladaptation to stress over time or "wear and tear" $[2,3]$. We know the continuous stressors from life's experiences, the physical environment in which one lives, works, plays, and prays as well as one's own biology can lead to some form of cardiovascular disease, the number one culprit for African American women. It has been said, "If you do what you've always done, you'll get what you've always gotten." We hope that the seven papers presented in this special issue will inspire new questions and stimulate innovative study designs and studies that provide depth in understanding African American women with the outcome of reducing and eliminating health disparities.

Karen Patricia Williams, $\mathrm{PhD}$

Guest Editor
Acknowledgments The Ohio State University, College of Nursing, Martha S. Pitzer Center for Women, Children and Youth.

Publisher's note Springer Nature remains neutral with regard to jurisdictional claims in published maps and institutional affiliations.

\section{References}

1. Karatsoreos IN, McEwen BS. Psychobiological allostasis: resistance, resilience and vulnerability. Trends $\operatorname{Cog} n \mathrm{Sci}$. 2011;15(12):576-84.

2. McEwen BS, Stellar E. Stress and the individual. Mechanisms leading to disease. Arch Intern Med. 1993;153(18):2093-101.

3. McEwen BS, Gianaros PJ. Central role of the brain in stress and adaptation: links to socioeconomic status, health, and disease. Ann N Y Acad Sci. 2010;1186:190-222. 